\title{
AS PERCEPÇÕES E A ATUAÇÃO DE PROFESSORAS DO ENSINO FUNDAMENTAL I DIANTE DO BULLYING ESCOLAR $^{1}$
}

\section{PERCEPTIONS AND FORMS OF ACTIONOF ELEMENTARY SCHOOL TEACHERS IN FRONT OF SCHOOL BULLYING}

\author{
Danyelle Shmith de Lima \\ Graduada em Pedagogia, Universidade do Oeste Paulista - Unoeste \\ Presidente Prudente, São Paulo - Brasil \\ danny.shmith@hotmail.com \\ Rosana Aparecida Tenorio Pereira \\ Graduada em Pedagogia, Universidade do Oeste Paulista - Unoeste \\ Presidente Prudente, São Paulo - Brasil \\ rosanatenoriolima@hotmail.com \\ Marcos Vinicius Francisco \\ Doutor em Educação, Universidade Estadual Paulista - UNESP \\ Presidente Prudente, São Paulo - Brasil \\ marcos_educa01@yahoo.com.br
}

\begin{abstract}
Resumo: A presente pesquisa teve como objetivo analisar as percepções e formas de atuação de professoras do Ensino Fundamental I diante de situações de bullying escolar. Nesta investigação, de natureza qualitativa, do tipo estudo de caso múltiplo, assumiu-se como procedimentos metodológicos a aplicação de questionários e a realização de entrevistas semiestruturadas com professoras de quatro escolas, cada uma delas localizadas em diferentes regiões de um município de pequeno porte do interior do Estado de São Paulo. Os resultados apontaram, conforme o relato das professoras, que os pátios das escolas são os locais onde mais ocorrem as manifestações de bullying, seguido das salas de aula. Das situações de intimidação sistemática vivenciadas, predominaram aquelas relacionadas à estrutura físico-corporal das vítimas. Embora a maioria das participantes tenha mencionado o contato com situações de bullying, na práxis pedagógica e/ou na instituição escolar onde atuam, poucas desenvolveram alguma atividade interventiva, em virtude de não terem formação ou apoio da gestão escolar para tal.
\end{abstract}

Palavras chave: Bullying escolar. Ensino Fundamental I. Práxis pedagógica.

Abstract: The present research had as objective to analyze the perceptions and forms of action of primary school teachers in front of school bullying. As methodological procedures, semi-structured interviews were carried out with the teachers of four schools, each one being located in different regions, in a small municipality in the interior of the São Paulo, Brazil. The research is qualitative, of the multiple case study type. According to the report of the teachers, the schools courtyards are the places where bullying occurs most often, followed by classrooms. Of the situations of systematic intimidation experienced, those linked to the physical and corporal structure of the victims predominated. Although most of the participants mentioned contact with bullying situations, in the pedagogical praxis or in the educational institution where they work, few developed any intervention activity, due to lack of training or support from school management.

Keywords: School bullying. Elementary school. Pedagogical praxis.

Para citar - (ABNT NBR 6023:2018)

LIMA, Danyelle Shmith de; PEREIRA, Rosana Aparecida Tenorio; FRANCISCO, Marcos Vinicius. As percepções e a atuação de profess oras do ensino fundamental I diante do bullying escolar. Eccos - Revista Cientifica, São Paulo, n. 54, p. 1-18, e13919, jul./set. 2020. Disponível em: https://doi.org/10.5585/eccos.n54.13919. 


\section{Introdução}

Ao considerar a escola como o primeiro local onde ocorre a socialização entre pares de diferentes culturas, condições socioeconômicas, etnias e gêneros, identifica-se uma diversidade sociocultural nem sempre aceita ou respeitada, sobretudo quando é posta em cheque diante de valores difundidos e tidos como hegemônicos no atual sistema, que por sua vez estão arraigados em processos de desigualdade social (FRANCISCO; LIBÓRIO, 2015; SILVA; COSTA, 2016).

Diante dos casos de intolerância e da intimidação sistemática, fruto das relações sociais produzidas cotidianamente, esta pesquisa restringiu-se às ocorrências no âmbito da escola, classificadas na literatura como bullying escolar. A respeito do processo histórico que deu origem aos estudos sobre o bullying, destaca-se o sueco Dan Olweus, pioneiro nas investigações sobre o tema. Suas motivações decorreram do suicídio de três adolescentes, perseguidos e intimidados por colegas em uma escola norueguesa, ainda na década de 1970 (OLWEUS, 1991).

No Brasil, as pesquisas relacionadas ao tema são mais recentes, uma vez que tiveram início somente no fim dos anos 1990 (FANTE, 2005). Entretanto, o bullying passou a receber maior visibilidade social após expressiva divulgação da tragédia ocorrida em uma escola do Rio de Janeiro, conhecida como o massacre de Realengo. Na ocasião (07 de abril de 2011), 12 crianças foram assassinadas, sendo que o atirador e também autor do massacre já havia estudado na referida unidade escolar. Segundo relatos, o autor dos disparos foi vítima de intimidação sistemática por parte dos colegas de escola. Este fato deu origem a Lei $n^{\circ}$ 13.277/2016, decretada e sancionada pela então Presidenta Dilma Rousseff, que instituiu o dia 07 de abril como o Dia Nacional de Combate ao bullying e à violência na escola (BRASIL, 2016).

Olweus (1993) caracteriza o fenômeno como a manifestação de comportamentos agressivos e intimidadores, dentre os quais se destacam as diversas técnicas de amedrontamento que resultam em atos violentos (físicos ou verbais), intencionais e repetitivos contra um indivíduo (vítima/alvo), decorrentes da ação de um agressor agindo sozinho ou coletivamente. Superando por incorporação essa conceituação, Francisco e Libório (2011) e Francisco e Coimbra (2019) apontam que o bullying deve ser entendido como uma manifestação humana, socialmente construída, sendo esse um aspecto negligenciado em parcela expressiva dos estudos sobre o assunto. $\mathrm{O}$ agressor e a vítima não são os únicos responsáveis pelas ocorrências, deve-se considerar a força dos valores sociais e crenças culturais que ensejam práticas pouco empáticas. 
Lisboa, Braga e Ebert (2009) classificam o bullying em dois tipos ${ }^{2}$, ou seja, o direto e o indireto. No bullying direto, os agressores são passíveis de identificação (a vítima sabe com exatidão quem está praticando), uma vez que utilizam agressões físicas, verbais e/ou materia is. Por vez, no bullying indireto, esse processo de identificação dos agressores é mais difícil, pois ele se consubstancia por meio de fofocas, boatos e difamações que, comumente, provocam o isolamento social das vítimas.

Para Fante (2005), dentre os diferentes papéis que os(as) estudantes assumem nas situações de bullying, destacam-se os(as) agressores(as), vítimas (típicas, provocadoras ou agressoras) e os(as) espectadores(as) (testemunhas). Contudo, não há consenso na literatura sobre essa classificação, visto que autores como Lopes Neto (2005) e Oliboni (2008) utilizamse das nomenclaturas alvos (vítimas) e autores (agressores).

Em linhas gerais, o bullying traz uma série de implicações e consequências para todos os envolvidos. Via de regra, as vítimas sofrem seus efeitos a curto prazo, dentre os quais se destacam as reações psicossomáticas, a insônia, a falta de amigos, o absenteísmo, a evasão escolar, além de comportamentos de risco à saúde, tais como o uso de drogas (LISBOA; BRAGA; EBERT, 2009; CHAVES; SOUZA, 2018; SILVA et al., 2018). A longo prazo, destacam-se a dificuldade de estabelecer relações interpessoais e o surgimento de quadros depressivos que, em casos mais extremos, podem levar ao suicídio (FANTE, 2005; CHAVES; SOUZA, 2018).

No que tange à figura dos agressores, há uma maior probabilidade dos mesmos se envolverem em atos infracionais no futuro (ZAINE; REIS; PADOVANI, 2010). É ponto assente que estes últimos também precisam de ajuda, visto que suas ações são social e culturalmente construídas (FRANCISCO; COIMBRA, 2015, 2019). Já os espectadores, mesmo que não tenham uma participação ativa nas ocorrências, podem desenvolver dificuldades de relacionamento entre seus pares (FANTE 2005; SILVA et al., 2017).

Mesmo diante das consequências elencadas, muitas vezes o bullying é banalizado tanto nos espaços escolares e quanto na sociedade. Há de se pensar em programas de combate mais amplos, que contemplem a heterogeneidade dos sujeitos sociais (FRANCISCO; LIBÓRIO, 2015; CHAVES; SOUZA, 2018), de forma que não fiquem restritos a nomear X ou Y como responsáveis pelas ocorrências.

Destarte, é necessário investigar a raiz do problema considerando os aspectos sociais, culturais, políticos e econômicos que influenciam a proliferação do bullying no cotidiano escolar. Há que se pensar em projetos mais amplos que tenham foco na superação das relações que existem no cotidiano escolar e para além dele, com o objetivo de prevenir a exclusão dos 
alunos. Se o bullying é uma manifestação humana, produzida culturalmente, a mesma sociedade que a pratica tem os meios e condições para superá-lo (FRANCISCO; LIBÓRIO, 2015).

Ventura, Vico e Ventura (2016) apontam a importância de o tema ser abordado desde a formação inicial de professores(as) e se estender aos processos de formação continuada. Mesmo diante das diversas tragédias anunciadas, as políticas públicas, os currículos e os estudos científicos ainda são dispersos. Segundo os referidos autores, é papel das instituições educativas a prevenção, o reconhecimento e o combate ao bullying escolar.

Alguns/Algumas professores(as) têm dificuldade em lidar com as ocorrências de bullying, mas é necessário ressaltar que isso não se dá por falta de vontade, e sim pela falta de conhecimentos sobre o assunto (TOGNETTA; VINHA; AVILÉS, 2014; VENTURA; VICO; VENTURA, 2016). Como consequência, muitas vezes as intervenções dos(as) professores(as) perante as ocorrências acabam por naturalizar o bullying enquanto uma violência habitual (SILVA; COSTA, 2016; VENTURA; VICO; VENTURA, 2016).

A responsabilidade de formar professores(as) capacitados(as), inicialmente, perpassa as universidades. Elas devem assumir um currículo que dialogue com as necessidades reais das escolas. No que tange ao bullying escolar, os(as) professores(as) precisam ser capacitados para preveni-lo, identificá-lo e intervir coletiva e individualmente, quando necessário. Um(a) professor(a) bem formado(a) se sente apto(a) a lidar com qualquer manifestação de violência (TOGNETTA; VINHA; AVILÉS, 2014; VENTURA; VICO; VENTURA, 2016).

Tal pesquisa se justificou diante da necessidade de se produzir mais conhecimentos acerca do tema, em consonância com a realidade brasileira, a fim de se romper com discursos advindos do senso comum que ainda o tratam como algo natural, diante do processo de desenvolvimento humano (FRANCISCO; LIBÓRIO, 2015; CHAVES; SOUZA, 2018). Partindo dos aspectos destacados anteriormente, assumiram-se as seguintes problemáticas para esta pesquisa: O que pensam os(as) professores(as) do Ensino Fundamental I sobre as situações de bullying na escola? Como agem diante de tais ocorrências? Na formação inicial ou nos espaços de formação continuada, o bullying escolar foi abordado? De que forma?

Como objetivo central a pesquisa primou por analisar as percepções e formas de atuação de professores(as) do Ensino Fundamental I perante situações de bullying escolar. 


\section{Procedimentos Metodológicos}

Na busca pela compreensão das percepções e atitudes dos(as) professores(as) do Ensino Fundamental I perante o bullying escolar, optou-se por uma pesquisa de natureza qualitativa, do tipo estudo de caso múltiplo. A pesquisa qualitativa responde a questões muito particula res, "[...] trabalha com o universo de significados, motivos, aspirações, crenças, valores e atitudes, o que corresponde a um espaço mais profundo das relações, dos processos e dos fenômenos que não podem ser reduzidos à operacionalização de variáveis" (MINAYO, 2002, p. 21-22).

Para Guerra (2014, p.11), a "abordagem qualitativa, [...] objetiva aprofundar-se na compreensão dos fenômenos que estuda - ações dos indivíduos, grupos ou organizações em seu ambiente ou contexto social". Para tanto, são valorizadas suas impressões e percepções.

Como destacado, nesta investigação, optou-se por abordar as percepções e ações de professores(as) do ensino fundamental I atuantes em distintas escolas vinculadas à rede municipal, sobre o bullying escolar. Tais aspectos alinham-se aos preceitos do estudo de caso múltiplo. Para Stake (2000), nessa modalidade procura-se captar a complexidade de um "sistema" em sua atividade, como por exemplo, nos casos onde vários indivíduos, simultaneamente, mesmo que em variadas realidades, vivenciam o mesmo processo.

\subsection{Instituições e participantes}

A pesquisa foi desenvolvida em quatro escolas de um município de pequeno porte do interior de São Paulo, nas quais estão matriculadas crianças do Ensino fundamental I, ou seja, estudantes do $1^{\circ}$ ao $5^{\circ}$ ano. A escolha por essas escolas se deu na expectativa de abarcar uma unidade de cada região do município investigado. O município, de acordo com o senso, possui aproximadamente 25 mil habitantes (IBGE, 2010). Essa diversidade de escolas contemplou sujeitos que atuam com populações em condições econômicas distintas. Por vez, o município foi escolhido em função das gestoras da Secretaria Municipal de Educação apresentarem postura de abertura e diálogo contínuo com as universidades localizadas na região, inclusive através de parcerias viabilizadas em projetos de pesquisa e extensão.

\subsection{Questionário e entrevistas semiestruturadas}

Com a autorização da Dirigente Municipal de Educação, procedeu-se ao contato com as direções de cada unidade escolar a fim de obter seu consentimento e explicitar os objetivos da 
pesquisa. Foi estipulado que a coleta de dados ocorreria antes das Aulas de Trabalho Pedagógico Coletivo (ATPCs), momento de maior disponibilidade dos(as) entrevistados(as). Em conversa com os(as) professores(as) que demonstraram interesse e que preencheram o Termo de Consentimento Livre Esclarecido (TCLE), foi entregue inicialmente um questionário com três questões abertas, a fim de utilizar as respostas para a seleção dos(as) professores(as) que participariam das entrevistas semiestruturadas. As questões do questionário objetivavam saber se os eventuais participantes sabiam o que era o bullying escolar; se havia casos de bullying em sua sala; e se já desenvolveram ou desenvolviam alguma intervenção/projeto a fim de coibir tal manifestação de violência.

Vale apontar que, durante o processo de aplicação do questionário, os(as) professores(as) que se opuseram participar da investigação ficaram numa posição defensiva, ao alegarem que a universidade apenas os(as) procura para realizar pesquisas e criticá-los(as). Mesmo diante da contraposição de tais argumentos e da explicação de que não era essa a perspectiva assumida pelos(as) pesquisadores(as) responsáveis por esta pesquisa, vários(as) docentes não se sentiram mobilizados(as) a contribuir. Dessa forma, 20 professores(as) das escolas selecionadas responderam as questões iniciais.

Em posse das respostas, os(as) participantes das entrevistas semiestruturadas foram aqueles(as) que souberam identificar o que era o bullying escolar; que já presenciaram situações em suas turmas; e que acenaram positivamente ou negativamente para o desenvolvimento de intervenções/projetos. Foi garantida a participação de dois/duas docentes por unidade escolar, totalizando oito participantes no segundo momento da investigação.

As entrevistas semiestruturadas foram realizadas de forma individual com as professoras selecionadas (08), e ocorreram por meio de um encontro em cada escola. As entrevistas foram gravadas. Em linhas gerais, as questões das entrevistas objetivaram: a) saber o que pensavam sobre as situações de bullying ocorridas no ambiente escolar; b) averiguar se o tema foi contemplado durante a formação inicial e se era abordado durante a formação continuada; c) conhecer os critérios utilizados para identificar situações classificadas como bullying; d) levantar as principais características percebidas pelas professoras no que tange à difusão do fenômeno; e) e os procedimentos adotados mediante tais ocorrências.

O material, coletado por meio das entrevistas, passou por um processo de transcrição, sendo organizado em eixos analíticos visando a problematização do presente estudo. O primeiro refere-se às 'Percepções, concepções e processos de identificação do bullying escolar", ao passo que o segundo diz respeito à "Abordagem do bullying escolar na formação inicial e continuada e os reflexos na práxis pedagógica". 


\title{
3 Análise e discussão dos dados
}

\subsection{Percepções, concepções e processos de identificação do bullying escolar}

Inicialmente, ao serem abordadas as impressões sobre o bullying nos espaços escolares, das oito entrevistadas, cinco responderam que cabia ao professor ter um olhar voltado para tais ocorrências. Abaixo se apresentam exemplos de falas:

\begin{abstract}
Para mim o bullying deve ser aniquilado do ambiente escolar, pois ele produz sérias consequências para a vida das crianças, tanto no seu desempenho escolar quanto na sua formação de personalidade, produzindo exclusão social, medo e, muitas vezes, o suicídio. Nós professores devemos estar atentos a todo o momento diante dessas ocorrências, para não serem passadas despercebidas. (VANESSA, ESCOLA 1, 2018).
\end{abstract}

Essas situações para mim, em minha formação era visto como algo natural. Mas hoje percebo que es ta palavra forte vem modificando a vida de muitas crianças no ambiente escolar e cabe a nós profes sores buscar uma formação continuada para saber lidar com estas questões preocupantes, pois queremos o melhor para nossos alunos. (MARIA, ESCOLA 2, 2018).

Nos exemplos supramencionados, identificou-se também a compreensão de que a formação de professores(as) é imprescindível para uma efetiva intervenção diante das ocorrências de intimidação sistemática. Nessa perspectiva, Pippi (2015), Ventura, Vico e Ventura (2016) apontam que é papel da comunidade escolar estar atenta a todo tipo de violência, de modo que não se tolere as manifestações explícitas ou implícitas. Para tanto, a comunidade escolar precisa refletir e buscar soluções para os problemas relacionados à violência produzida num contexto específico. Esse entendimento questiona, por exemplo, as perspectivas que buscam apenas criminalizar o bullying escolar ao tirar dos agentes educacionais a possibilidade de resolver aquilo que foi produzido socialmente através do diálogo e de ações interventivocoletivas.

Tal compreensão coaduna com o entendimento de que um simples programa de intervenção não seja capaz de extirpar tais situações. Daí a importância de se considerar o fenômeno em intersecção com os aspectos sociais, políticos, econômicos e culturais que influenciam as condutas dos(as) estudantes (FRANCISCO; LIBÓRIO, 2015; CHAVES; SOUZA, 2018). Eles(as) precisam ser levados(as) a entenderem de que forma a intimidação sistemática se produz no ambiente escolar, bem como os valores difundidos no sistema capitalista que culminam em práticas de ódio e de intolerância.

Ao serem questionadas sobre os locais onde predominam as ocorrências de bullying, todas as participantes sinalizaram o pátio das instituições, seguido das salas de aula, como exemplificado nos relatos abaixo: 
$\mathrm{Eu}$ acho que o bullying é pior no intervalo, mas dentro da sala também acontece. Mas como na sala a gente fica mais em cima, no momento você já chama atenção e intervém. Já no intervalo por serem muitas crianças, às vezes, acaba passando e eles não informam os tios (inspetores), só reclamam na sala para mim de alguma criança de outra sala ou algo do tipo. Então acredito que no intervalo ocorra mais, por serem poucos inspetores para tantas crianças. (ESTER, ESCOLA 1, 2018).

As situações ocorriam desde a sala até o intervalo. Mas no intervalo era mais intenso, pois eles voltaram de uma forma diferente, eu notava. Acho que porque não tinha muita gente vendo né, então podiam falar o que pensavam. (MARIA, ESCOLA 2, 2018).

Na sala ocorre, mas fora dela é com mais frequência, pois na volta do intervalo é que ouvia mais conversa, sem a monitoria é maior. Na sala por ter a autoridade do professor eles ficam acanhados, mas não que não poderia acontecer também, mas fora era com mais frequência. (BRUNA, ESCOLA 3, 2018).

Tais dados corroboram as constatações realizadas por Ventura, Vico e Ventura (2016), devido ao fato de que os pátios escolares, assim como os banheiros e refeitórios, possuem menor vigilância, todavia os autores ressalvam que devemos ficar atentos, pois o bullying não ocorre apenas nesses locais. É importante destacar que tais dados estão assentados sob o olhar das professoras participantes desta investigação, visto que em pesquisas desenvolvidas sob a perspectiva dos estudantes, no contexto brasileiro, as salas de aula foram consideradas os espaços de maior difusão dos casos de intimidação sistemática (FANTE, 2005; FRANCISCO; LIBÓRIO, 2009; ZEQUINÃO et al., 2016).

Outro questionamento feito às participantes referiu-se a suas percepções sobre o sexo dos envolvidos nas situações de bullying. A maioria apontou o sexo masculino, até mesmo no papel de agressores. Na sequência explicitam-se alguns exemplos de falas:

De conflitos maiores foram com meninos. As meninas eram as que ficavam quietinhas, manipulando a situação. Os meninos tinham muito de quererem se aparecer mais, então muitas vezes saiam no braço para dis putar força e masculinidade (SILVIA, ESCOLA 3, 2018).

$\mathrm{Na}$ maioria dos casos principalmente o agressor vem por parte dos meninos, geralmente os meninos apresentam este tipo de comportamento (FERNANDA, ESCOLA 4, 2018).

Embora os posicionamentos dos(as) professores(as) que vivenciam o dia a dia da educação básica devam ser considerados, é oportuno destacar que as atitudes dos(as) estudantes fazem parte de um sistema de relações sociais que demarcam as influências culturais. Não obstante, há vários estudos evidenciando que tanto meninos quanto meninas atuam como agressores(as) em situações de intimidação sistemática. (FRANCISCO; COIMBRA, 2015; ZEQUINÃO et al.,2016; SILVA et al., 2018).

Pippi (2015) complementa sobre a necessidade de compreender as atitudes dos(as) envolvidos(as) e o porquê de sua ocorrência dentro das escolas, além do fato de que elas não 
devem ser entendidas de maneira isolada, mas dentro de um contexto social, histórico e cultural frente às múltiplas determinações do atual modelo de sociedade. Nesse sentido, compreende-se que as ações ocorridas dentro dos muros escolares são reflexo da materialidade e objetividade das relações humanas, legitimadas mediante os saberes produzidos socialmente (REIS; CARVALHO, 2017).

\subsection{Abordagem do bullying escolar na formação inicial e continuada e os reflexos na práxis pedagógica}

Ao questionar as participantes sobre as vivências diante do tema bullying escolar, seja na formação inicial e/ou continuada, bem como a forma com que o mesmo foi abordado, constatou-se que em alguns casos ele foi debatido, mas apenas superficialmente. Abaixo são apresentados alguns exemplos dos apontamentos feitos por elas:

Depois da faculdade não me lembro de termos nenhuma formação específica sobre o bullying. Estou na rede há pouco tempo, ingress ei ano pas sado no ensino fundamental, então ainda estou começando né [...], mas na faculdade a gente ouvia bastante falar sobre isso. Eu lembro que a gente assistia alguns filmes, falando sobre o bullying de forma mais geral e, às vezes, abordava o que a gente deveria fazer, estar sempre conversando com as crianças e orientando, mas apenas na época da faculdade mesmo (ESTER, ESCOLA 1, 2018).

$\mathrm{Na}$ faculdade sim, via com frequência sobre o conceito, quais atitudes são ad equadas em determinados momentos. Porém, é só na prática que sabemos como lidar, porque cada caso é um caso e não podemos generalizar. Nos ATPCs nunca abordaram o assunto, pelos menos desde quando eu leciono aqui (VANESSA, ESCOLA 1, 2018).

Não foram abordados! Em nenhum momento da minha faculdade essa palavra compareceu. Acredito ser um termo muito novo, perto da época que me formei. Mas nos ATPC sim, foram trabalhadas essas questões, como uma forma de ajudar os professores a perceber as situações e intervir de forma mais ampla. Eu não tive muitos casos de bullying nesta instituição graças a Deus (MARIA, ESCOLA 2, 2018).

$\mathrm{Eu}$ me formei no ano de 2000 e, sinceramente, na época da minha formação essa palavra, acredito eu que seja um termo recente, pois essas situações já ocorriam, mas não eram retratadas da forma que é agora [...]. Então, foi dentro da formação continuada mesmo que esse termo apareceu e começou a se discutir mais, a questão dos direitos. Nos ATPCs foi mais por exigência dos professores, porque eram situações que não sabíamos mais como lidar e precisávamos de ajuda para intervir nessas situações (SILVIA, ESCOLA 3, 2018).

Embora não haja consenso na fala das participantes, é evidente que as mais jovens tiveram contato com o tema em sua formação inicial, algo que é plenamente compreensível tendo em vista que a emergência do tema no contexto brasileiro se deu a partir dos anos 2000 (FANTE, 2005; ANTUNES; ZUIN, 2008). A despeito de três escolas terem realizado discussões sobre o tema em seus ATPCs - à exceção da escola 1 -, conforme o relato das participantes, urge a necessidade de uma formação mais consistente, capaz de superar o caráter 
informativo sobre o assunto. Os(as) professores(as) precisam se apropriar, inclusive, de literaturas científicas, de modo a objetivar tais conhecimentos e lidar com as situações de bullying por meio de intervenções mais amplas que conduzam os estudantes a refletirem sobre os motivos que ocasionam a produção de situações de intimidação sistemática (LIMA; PEREIRA; FRANCISCO, 2018).

Ventura, Vico e Ventura (2016) reforçam a necessidade de preparação dos(as) educadores(as), seja na formação inicial, seja na continuada, capacitando-os(as), para que tenham condições de identificar, prevenir e combater o bullying de maneira efetiva. No que tange aos momentos de formação continuada, há que se garantir que a comunidade escolar seja sensibilizada para não banalizar e negligenciar as situações de violência vivenciadas pelos(as) estudantes. O embasamento científico coloca-se como um instrumento fundamental para auxiliar qualquer tipo de intervenções a fim de se romper com justificativas e ações ancoradas no senso comum (LIMA; PEREIRA; FRANCISCO, 2018).

As professoras também foram questionadas sobre os acontecimentos que já presenciaram em sua práxis pedagógica, caracterizados como bullying escolar. Segundo os relatos apresentados na sequência, constata-se uma propensão de intimidações ligadas à estrutura físico-corporal das vítimas, de tal forma que há a rejeição por parte daqueles(as) que não se adéquam aos padrões socialmente normatizados.

\begin{abstract}
Sim, na minha sala do ano passado havia muitos alunos que gostavamde menosprezar os outros. Então informei a direção que faria uma intervenção diferente e mesmo contra muitas opiniões eu fiz, cheguei na sala e comecei a ofender esses alunos que gostavam de intimidar os outros, mas claro, com palavras que não me prejudicaria, comecei a ignorá-los e eu via no olho deles que eles estavam se sentindo mal e exclú́dos e persisti nisso durante toda aula. Fomos à quadra e estes alunos ficaram de canto, conversando sozinhos, cois a que nunca haviam feito no decorrer do ano letivo. Ao voltar para a sala conversei com eles e eles choraram muito e disseram que não sabiam o quanto era ruim ouvir ofensas o tempo inteiro. Não acredito que tenham mudado da água para o vinho, mas eu vi uma melhora significativa em suas atitudes (VANESSA, ESCOLA 1, 2018).
\end{abstract}

Nesta escola eu não presenciei muitas situações alarmantes, não. Mas em outras escolas sim, não vou citar o nome para não comprometer a gestão escolar, mas lá a situação era outra, os alunos eram terríveis, faziam o que queria e ninguém tomava uma atitude, o motivo eu não sei. Os alunos costumavamse insultar por características físicas, coisas do tipo: Você é gorda, seu cabelo é duro e outras coisas que magoam (MARIA, ESCOLA 2, 2018).

Sim, eu tinha uma aluna que era mais gordinha que os amigos, ela se aceitava como ela era, mas se incomodava muito com os apelidos que colocavam nela. Nesta escola ainda não presenciei nada por enquanto (GABRIELA, ESCOLA 2, 2018). 
No decorrer do ano passado, eu presenciei sim esse bullying porque eu tinha uma menina na minha turma que era de baixa estatura, gordinha e negra. Então ela tinha todos os fatores que não eram bem vistos dentro do padrão, então por muitas vezes eu tive que parar a aula e fazer um trabalho dentro do meu pequeno gru po, ela chorava, ficava acanhada e eu não achava legal (BRUNA, ESCOLA 3, 2018).

Sim, nesta escola e em outras eu vejo ocorrendo principalmente com crianças obesas e negras (FERNANDA, ESCOLA 4, 2018).

Tais achados coadunam com os apontamentos de Antunes e Zuin (2008), para quem o preconceito constitui-se como um fator de risco e que determina influências diretas na propagação do fenômeno, paripassu, reforça estereótipos físico-corporais e modos de ser e agir que passam a ser aceitos ou rejeitados culturalmente. Oliveira (2015) pondera sobre as influências culturais, visto que um aspecto a ser combatido e problematizado junto aos(às) estudantes refere-se à dimensão da competição, inerente ao sistema capitalista.

Conforme Oliveira (2015), a competição é reforçada, muitas vezes, pelos(as) próprios(as) docentes como estratégia para despertar o interesse dos(as) estudantes em relação às atividades escolares, mesmo que tal recurso não seja cientificamente aceito. É importante não perder de vista que a competição exacerbada gera frustações, ao fazer que os(as) estudantes prendam-se a padrões preestabelecidos e que vão sendo internalizados e legitimados socialmente em perspectivas etnocêntricas.

Como exemplo, menciona-se os concursos de miss e mister promovidos nas escolas, eventos que, por sua vez, reforçam os padrões difundidos pela mídia e meios de comunicação, bem como ações de premiação de estudantes com bom desempenho acadêmico, em detrimento dos que apresentam dificuldades de aprendizagem, dentre outras. Nessa perspectiva, Francisco e Libório (2015) acrescentam que o bullying reflete a não aceitação das diferenças socioculturais, reforçadas por uma sociedade que propaga o individualismo.

É importante ponderar ainda que, quando se defende que os(as) professores(as) devem agir perante situações de intimidação sistemática, não se compactua com os exemplos de intervenção mencionados pela professora Vanessa. Até mesmo porque suas ações foram permeadas pela dimensão da violência. Daí é que ganham consistência os pressupostos da pedagogia histórico-crítica, já que os(as) professoras precisam ter clareza de que o ponto de partida para qualquer intervenção é a própria prática social. Do ponto de vista pedagógico, estudantes e professores(as) se encontram em níveis distintos de compreensão da prática social (conhecimento e experiência), a despeito de que os(as) professores(as) tenham ainda uma síntese precária desse primeiro momento (coletivo em que atuam e como o fenômeno se manifesta), bem como os(as) estudantes uma compreensão sincrética. É por meio da 
problematização que se podem identificar as questões que precisam ser sanadas e o conhecimento necessário em tal processo (SAVIANI, 2012).

Segundo Saviani (2012), é por meio da instrumentalização que os (as) professores(as) mediarão junto aos estudantes os instrumentos teóricos e práticos capazes de equacionar os problemas identificados na prática social, qual seja, as intimidações sistemáticas, como no caso em apreciação. Assim, ocorrerá uma catarse, ou seja, "a efetiva incorporação dos instrumentos culturais, transformados agora em elementos ativos de transformação social” (p. 71). É lógico que a ideia de transformação está ancorada à uma perspectiva de que professores(as) e estudantes tenham consciência dos condicionantes histórico-sociais na educação, bem como que qualquer atividade interventiva deverá estar atrelada à ideia de superação do atual sistema de relações sociais, devido ao fato de que o bullying escolar é um fenômeno produzido histórico e contextualmente.

Nessa perspectiva, a própria prática social será o ponto de chegada, não mais compreendida em termos sincréticos pelos(as) estudantes, que agora ascendem ao nível sintético, ou seja, da síncrese à síntese. Por conseguinte, a compreensão dos(as) professores(as) se tornará mais orgânica (SAVIANI, 2012).

Tais elementos teóricos são necessários, sobretudo, para problematizar os questionamentos feitos às professoras, se já haviam presenciado alguma situação de bullying nas escolas onde atuam, e quais os tipos de intimidação mais difundidos. Os dados apresentados na sequência complementam aqueles problematizados anteriormente, bem como as discussões empreendidas sobre as características presentes nas situações de violência denunciadas:

Eu observo mais o bullying direto em relação à aparência, pois são coisas mais nítidas de serem observadas, são a primeira impressão que temos do outro e é algo que não podemos mudar muitas vezes, então afeta e muito (MARIA, ESCOLA 2, 2018).

As crianças apontam geralmente para o bullying direto em relação aos mais gordinhos e os que possuem mais dificuldades, seja comportamental ou pedagógica, is to é, pessoas mais tímidas e fechadas e aqueles que têm algum distúrbio de aprendizagem, como o déficit de atenção (GABRIELA, ESCOLA 2, 2018).

Presenciei bullying de todos os tipos, mas como disse, o físico não era tão evidente. Mas o social era muito frequente, poucas pessoas conseguiam identificar. [...] $\mathrm{Na}$ minha sala me chamou muita atenção estas questões sociais reproduzidas por eles dentro da sala de aula, sendo muito marcante, coisas do tipo: "Você é filho de quem", "Você passa fome", "Você é favelado" e outros insultos. Desta forma as características físicas eram esquecidas. Mas na escola ocorria muitas agres sões físicas, uma escola muito violenta, de certa forma, justificada pela violência social que sofriam todos os dias (SILVIA, ESCOLA 3, 2018).

Mais bullying direto a respeito de caracterís ticas físicas como a obesidade e a magreza, e também o indireto por meio de exclusão social dos grupos. (GIOVANA, ESCOLA 4, 2018). 
Todas essas formas de difusão e propagação da intimidação sistemática nominadas de bullying direto pelas professoras participantes da pesquisa corroboram os achados de Marcolino et al., (2018, p. 3), uma vez que "dentre os tipos de bullying sofridos pelos estudantes, o bullying psicológico (espalhar fofocas, excluir de atividades, xingar, ameaçar, ridicularizar) predominou nas situações", aspectos relatados por um total de $23,3 \%$ dos(as) estudantes do referido estudo, ou seja, aqueles(as) que já sofreram este tipo de violência escolar. Os autores complementam que essa modalidade de bullying, por estar associada à uma dimensão que muitas vezes não deixa marcas físicas, contribui para o seu processo de naturalização nas relações interpessoais dentro dos espaços escolares.

Outra dimensão contemplada nas entrevistas refere-se a averiguar se as professoras já desenvolveram e/ou desenvolvem algum trabalho e/ou atividade interventiva para problematizar e minimizar as ocorrências de intimidação sistemática. A maioria das participantes identificaram situações de bullying em sua práxis pedagógica ou na instituição escolar, embora apenas três delas relataram ter desenvolvido alguma atividade interventiva. As demais alegaram não ter formação ou apoio da gestão escolar para tal. Abaixo são apresentados trechos das participantes que desenvolveram intervenções:

\footnotetext{
Nos anos finais, $4^{\circ}$ e $5^{\circ}$ ano, desenvolvemos algo sim, pois já vi cartazes pela escola, no ano passado. Orientamos também os responsáveis nas reuniões, para haver essa parceria de quando ocorrer os casos, chamamos eles para conversarem. A direção também nos dá base para lidar com es sas situações, quando foge do meu controle, eles (direção) está sempre intervindo e ajudando nesse projeto, mesmo não sendo específico (ESTER, ESCOLA 1, 2018).
}

Esta escola costuma apenas nos orientar nos HTPC, os projetos ficam por conta dos profes sores que entendem o tipo de intervenção que a sua turma precisa né. Mas em outras escolas que lecionei não podíamos fazer projetos e nem tocar no assunto, devíamos negar até a morte essas ocorrências emnoss a instituição e eu achava errado, pois isso não amenizava as ocorrências, onde já se viu fingir que nunca existiu (MARIA, ESCOLA 2, 2018).

Primeiro eu trabalhei o respeito, eles deveriam entender até aonde era o outro e até aonde era ele, respeitando o outro. E depois trabalhei a questão das diferenças, pois nós não somos iguais, todo mundo é diferente do outro, temos defeitos e qualidades, mas devemos buscar sempre as qualidades. Trouxe muitos textos informativos, reportagens e fatos que ocorriam na televisão, onde eles teriam acesso de buscar. Foi um trabalho que foi estendido por um ano inteiro, chegou a funcionar, pois a menina que sofria bullying aumentou sua autoestima e a sala de um modo geral, começou a respeitar o outro (BRUNA, ESCOLA 3, 2018).

Dos relatos supramencionados, merece destaque a fala da professora Maria, vinculada à escola 2, ao apontar que, em algumas escolas nas quais lecionou, era coibida de mencionar e, por conseguinte, intervir no assunto, como uma forma de camuflar sua existência naqueles espaços, em específico. Oliveira $(2015$, p. 19) salienta que as instituições educacionais não 
podem ficar indiferentes "ao tema e nem naturalizar os fatos, como se fosse apenas uma 'brincadeira' ". Ainda de acordo com autor, banalizar as ocorrências favorece o descaso e o comprometimento educativo que se deve assumir com o ser humano e a sociedade.

Apenas a professora Bruna, da escola 3, ressaltou de forma mais consistente o processo de intervenção realizado. Por vez, embora as ações da professora Ester, da escola 1, devam ser valorizadas, elas ainda são pontuais, ou seja, não focam na raiz do problema. Perante essa questão, Francisco e Libório (2015) ressalvam:

Há a ilusão de que um simples programa de intervenção ou a elaboração de uma política pública em âmbito nacional seriam capazes de erradicá-lo. Como consequência, se estaria por ignorar várias dimensões que exercem influência em sua configuração, tais como, os aspectos sociais, políticos, econômicos e culturais, como se a problemática fosse decorrente, apenas, das relações isoladas entre um ou vários sujeitos na realidade, desconsiderando-se a determinação da totalidade social nesse processo. Esses são desafios que precisam ser repensados, até mesmo porque se for estabelecida uma relação com os programas de intervenção, como os de combate ao bullying escolar, percebe-se que na maioria das vezes os mesmos advêm de relações verticais que não contemplam a heterogeneidade dos sujeitos sociais (FRANCISCO; LIBÓRIO, 2015, p. 18-19).

Para os autores, a formulação de programas/políticas sociais de intervenção demanda um olhar mais crítico a fim de se evitar a adaptação dos sujeitos ao atual modelo de sociedade. Acentuam, ainda, o potencial da literatura, dos diferentes gêneros textuais, das obras de arte, do teatro, da música, da dança e dos filmes como um meio de favorecer uma análise da realidade e do bullying escolar para além de sua aparência fenomênica.

\section{Considerações finais}

Esta pesquisa, conduzida sob a perspectiva de professoras do ensino fundamental I, deve ser enaltecida, sobretudo, ao visibilizar um público que pouco comparece nas literaturas sobre o tema no contexto brasileiro. Ao serem questionadas sobre os locais onde predominam as ocorrências de bullying, todas as participantes sinalizaram o pátio das instituições, seguido das salas de aula.

No que tange à percepção das participantes sobre o sexo dos envolvidos nas situações de bullying, a maioria apontou o sexo masculino, em especial, no papel de agressores, ao enfatizar que as meninas são mais "quietinhas". Há que se ponderar que tais dados não podem ser interpretados de maneira isolada, sobretudo porque as ações dos indivíduos são situadas histórica e culturalmente. Embora não seja uma regra geral, assiste-se a um modelo de sociedade que encoraja os homens as serem mais agressivos e a afirmarem sua masculinidade, 
inclusive em situações tidas como violentas. Por oposição, as meninas são estimuladas a manter uma postura de docilidade e submissão.

No que diz respeito ao contato com o tema do bullying escolar na formação inicial e/ou continuada, não houve concordância nos relatos das professoras. As mais jovens relataram ter visto o tema na formação inicial, o que coaduna com o surgimento das discussões no contexto brasileiro - com maior ênfase a partir dos anos 2000. Já as professoras com maior tempo de formação mencionaram a emergência das discussões, em suas trajetórias, somente por meio dos ATPCs, ainda que de forma pontual e paliativa.

Quando questionadas sobre os eventos que já presenciaram na práxis pedagógica e que se caracterizam como bullying escolar, conforme os relatos das participantes, predominam as intimidações ligadas à estrutura físico-corporal das vítimas, manifestadas como uma forma de rejeição perante aqueles(as) que não se adéquam aos padrões instituídos social e culturalmente. Merece ênfase o fato de que a maioria das participantes mencionou o contato com situações de bullying na práxis pedagógica e/ou na instituição escolar onde atuam, contudo, parcela expressiva sequer desenvolveu alguma atividade interventiva.

Tem-se a clareza de que não é qualquer tipo de atividade interventiva que irá eliminar as ocorrências de bullying. Posto isso, os estudantes, familiares e respectivos agentes escolares necessitam assumir uma perspectiva que considere o fenômeno como uma construção social e cultural. É imperioso compreender como a intimidação sistemática se produz no ambiente escolar, além dos valores difundidos no sistema capitalista que, em maior ou menor grau, repercutem em situações de ódio, intolerância e etnocentrismo, ingredientes do bullying escolar.

\footnotetext{
${ }^{1}$ Esta pesquisa foi financiada pelo Conselho Nacional de Desenvolvimento Científico e Tecnológico (CNPq).

${ }^{2}$ Silva e Costa (2016) salientam, por se tratar de um tema que nas últimas décadas atraiu diversos(as) pesquisadores(as), percebe-se algumas divergências em relação a sua classificação. Alguns o dividem em duas categorias - bullying direto e indireto ou físico e não físico (LISBOA; BRAGA; EBERT, 2009).
}

\section{Referências}

ANTUNES, Deborah Christina; ZUIN, Antônio, Álvaro Soares. Do bullying ao preconceito: os desafios da barbárie à educação. Revista Psicologia \& Sociedade, Porto Alegre, v. 20, n. 1, p. 33-41, jan./abr. 2008. 
BRASIL. Lei $\mathrm{n}^{\circ}$ 13.277, de 29 de abril de 2016. Institui o dia 7 de abril como o dia nacional de combate ao bullying e à violência na escola. Diário Oficial [da República Federativa do Brasil], Brasilia, DF, v. 153, n. 82, 02 mai. 2016, Seção I, p. 3.

CARVALHO, Gabriel Zamian de; REIS, Aparecido Francisco dos. Bullying escolar: a violência e preconceito entre estudantes do ensino fundamental em Campos Grande, MS. Multitemas, Campo Grande, MS, v. 22, n. 51, p. 69-89, jan./jun. 2017.

CHAVES, Denise Raissa Lobato; SOUZA, Mauricio Rodrigues de. Bullying e preconceito: a atualidade da barbárie. Bras. Educ., Guamá, PA, v. 23, p. 10-17, abr. 2018.

FANTE, Cleo. Fenômeno Bullying: como prevenir a violência nas escolas e educar para a paz. Campinas: Verus, 2005.

FRANCISCO, Marcos Vinicius; LIBÓRIO, Renata Maria Coimbra. Um estudo sobre bullying entre escolares do ensino fundamental. Psicologia: Reflexão e Crítica, Porto Alegre, v. 22, n. 2, p. 200-207, 2009.

FRANCISCO, Marcos Vinicius; LIBÓRIO, Renata Maria Coimbra. Notas sobre alguns desdobramentos necessários nos programas de combate ao bullying escolar: uma análise histórico-cultural. Interacções, Lisboa, n. 38, p. 7-27, 2015.

FRANCISCO, Marcos Vinicius; LIBORIO, Renata Maria Coimbra. Reflexões sobre a superação de concepções individualizantes sobre o bullying escolar. In: RIBEIRO, Arilda Inês Miranda; VIOTTO FILHO, Irineu Aliprando Tuim; FURKOTTER, Monica; LEITE, Yoshie Ussami Ferrari. (Orgs.). Educação contemporânea: caminhos, obstáculos e travessias. São Paulo: Cultura Acadêmica. 2011, p. 61-78.

FRANCISCO, Marcos Vinicius; COIMBRA, Renata Maria. Análise do bullying escolar sob o enfoque da psicologia histórico-cultural. Estud. psicol.

(Natal), Natal, v. 20, n. 3, p. 184-195, set. 2015.

FRANCISCO, Marcos Vinicius; COIMBRA, Renata Maria. Bullying escolar e os processos de resiliência em-si sob a ótica da teoria histórico-cultural. Educação temática e digital, Campinas, v. 21, n. 1, p. 145-163, 2019.

GUERRA, Elaine Linhares de Assis. Manual de pesquisa qualitativa. Grupo Änima Educação, Belo Horizonte, 2014.

LIMA, Danyelle Shmith; PEREIRA, Rosana Aparecida Tenorio; FRANCISCO, Marcos Vinicius. Notas sobre os programas e leis de enfrentamento ao bullying escolar, Colloquium Humanarum, Presidente Prudente, v. 15, n. esp. 1., p. 212-219, jan./mar. 2018.

LISBOA, Carolina; BRAGA, Luiza de Lima; EBERT, Guilherme. O fenômeno bullying ou vitimização entre pares na atualidade: definições, formas de manifestação e possibilidades de intervenção. Contextos Clínicos, São Leopoldo, v. 2, n.1, p. 59-71, jan./jun. 2009. 
LOPES NETO, Aramis Antonio. Bullying: comportamento agressivo entre estudantes. $J$. Pediatr. (Rio J.), Porto Alegre, v. 81, n. 5, p. 164-172, nov. 2005.

MARCOLINO, Emanuella de Castro; CAVALCANTI, Alessandro Leite; PADILHA, Wilton Wilney Nascimento; FRANCISCO, Arnoldo Nunes de Miranda; CLEMENTINO, Francisco de Sales. Bullying: prevalência e fatores associados à vitimização e à agressão no cotidiano escolar. Texto contexto - enferm., Florianópolis, v. 27, n. 1, e5500016, 2018.

MINAYO, Maria Cecilia de Souza. Pesquisa Social: Teoria, método e criatividade. 21. ed. Petrópolis: Vozes, 2002.

NASCIMENTO, Alcione Melo Trindade do; MENEZES, Jaileila de Araújo. Intimidações na adolescência: expressões da violência entre pares na cultura escolar. Psicol. Soc., Belo Horizonte, v. 25, n. 1, p. 142-151, 2013.

OLIVEIRA, Edjôfre Coelho de. O bullying na escola: como alunos e professores lidam com esta violência? Fundamentos, Teresina, v. 2, n. 1, p. 118-137, 2015.

OLIBONI, Samara Pereira. O bullying como violência velada: a percepção e ação dos professores. 2008. 109f. Dissertação (Mestrado em Educação Ambiental). Universidade Federal do Rio Grande, Rio Grande, 2008.

OLWEUS, Dan. Bully/victim problems among schoolchildren: basic factos and effects of a school-based intervention program. Hillsdale: N. J. Erlbaum, 1991.

OLWEUS, Dan. Bullying at school: what we know and what we can do. London, WilleyBlackwell, 1993.

PIPPI, Izabel Cristina Lorenzen. Bullying: relações de poder na escola. 2015. 19f. Trabalho de Conclusão de Curso (Licenciatura em Ciências Sociais). Universidade Federal de Santa Maria (UFSM). Santa Maria, RS. 2015.

SAVIANI, Dermeval. Escola e democracia. 42. ed. Campinas: Autores Associados, 2012.

SILVA, Cíntia Santana e; COSTA, Bruno Lazzarotti Diniz. Opressão nas escolas: o bullying entre estudantes do ensino básico. Cad. Pesqui., São Paulo, v. 46, n. 161, p. 638663, set. 2016.

SILVA, Jorge Luiz da; OLIVEIRA, Wanderlei Abadio de; MELLO, Flávia Carvalho Malta de; ANDRADE, Luciane Sá de; BAZON, Marina Rezende; SILVA, Marta Angélica Iossi. Revisão sistemática da literatura sobre intervenções antibullying em escolas. Ciência \& Saúde Coletiva, Ribeirão Preto-SP, v. 22, n. 7, p. 2329-2340, 2017.

SILVA, Jorge Luiz da; MELLO, Flávia Carvalho Malta de; OLIVEIRA, Wanderlei Abadio de; PRADO, Rogério Ruscitto do; Silva, Marta Angélica Iossi; MALTA, Deborah Carvalho. Vitimização por bullying em estudantes brasileiros: resultados da pesquisa nacional de saúde do escolar (pense). Texto Contexto Enferm., Florianópolis, v. 27, n. 3, p. 1-10, ago. 2018. 
STAKE, Robert E. Investigación con estudios de casos. 2. ed. Madrid: Ediciones Morata, 2000.

TOGNETTA, Luciene Regina Paulino; VINHA, Telma Pileggi; AVILÉS, José Maria Martinez. Bullying e a negação da convivência ética: quando a violência é um valor. Revista INFAD de Psicología - International Journal of Developmental and Educational Psychology, v. 7, n. 1, p. 315-322, 2014.

VENTURA, Alexandre; VICO, Beatriz Pedrosa; VENTURA, Rosângela. Bullying e formação de professores: contributos para um diagnóstico. Ensaio: aval. pol. públ. Educ., Rio de Janeiro, v. 24, n. 93, p. 990-1012, dez. 2016.

ZAINE, Isabela; REIS, Maria de Jesus Dutra dos; PADOVANI, Ricardo da Costa. Comportamentos de bullying e conflito com a lei. Estudos de Psicologia, Campinas, v. 27, n. 3, p. 375-382, jul./set. 2010 .

ZEQUINÃO, Marcela Almeida; MEDEIROS, Pâmella de; PEREIRA, Beatriz; CARDOSO, Fernando Luiz. Bullying escolar: Um fenômeno multifacetado. Educ. Pesqui., São Paulo, v. 42, n. 1, p. 181-198, jan./mar. 2016. 